\title{
Erken çocukluk çağı çürükleri ve etiyolojisi: Güncel literatür derlemesi
}

\author{
Adem Kuşgöz ${ }^{1}$, Sema Aydınoğlu²
}

Selcuk Dent J, 2016; 3: 39-48

Basvuru Tarihi: 20 Nisan 2016 Yayına Kabul Tarihi: 26 Nisan 2016

\begin{abstract}
öz
Erken çocukluk çağı çürükleri ve etiyolojisi: Güncel literatür derlemesi

Yetmiş bir aylık ve daha küçük çocuklardaki bir veya daha fazla çürük lezyonu (kavite oluşmuş ya da oluşmamış), diş kaybı (çürüğe bağı) veya dolgulu süt dişinin olması erken çocukluk çağı çürüğü (EÇÇ) olarak tanımlanmaktadır. Bu derlemenin amacl; okul öncesi çocuklarda görülen en yaygın ve agresif hastalıkların başında gelen erken çocukluk çağı çürüklerinin tanımı, prevelansı ve risk faktörleri ile alakalı güncel literatür bilgilerinin aktarılmasıdır.
\end{abstract}

\section{ANAHTAR KELIMELER}

Diş çürüğü, okul öncesi çocuklar, risk faktörleri

Erken çocukluk çağı; fiziksel, zihinsel ve ruhsal yönden önemli olan üç-beş yaş arasındaki süreci kapsayan bir dönemdir. Yaklaşık olarak altıncı ayda sürmeye başlayan süt dişlerinin sayısının bu dönemin sonunda yirmiye ulaştığı görülmektedir. Süt dişleri beslenme, konuşma, çenelerin gelişimi ve estetiğe katkıda bulunmalarının yanı sıra kendilerinden sonra sürecek olan daimi dişlerin yerlerini korumaları nedeniyle bilinen en iyi yer tutuculardır. Bu özellikleri ile sağlıklı dişlenmenin anahtarı sayılan süt dişlerinin erken kaybı, ileride geçici ya da kalıcı olabilecek okluzyon bozukluklarına, estetik sorunlara, beslenme problemlerine, anormal dil alışkanlıklarına, konuşma bozukluklarına ve psikolojik sorunlara yol açabilmektedir (Law 2013). Bu nedenle, fizyolojik düşme yaşına kadar süt dişlerinin sağlıklı ve fonksiyonel bir şekilde ağızda tutulması çocuk diş hekimliğinin esas hedeflerindendir.

\section{ABSTRACT \\ Early childhood caries and risk factors: A literature review}

Early childhood caries (ECC) is defined as the presence of one or more carious lesions (with or without cavitated), extracted tooth (due to dental caries) or filled tooth surfaces in any primary tooth in children 71 months of age or younger. The aim of this report is to present definition, prevalence and risk factors of early childhood caries which is the most common seen and aggressive disease in preschool children.

\section{KEYWORDS}

Dental caries, preschool children, risk factors

\section{Erken çocukluk çağı çürüklerinin tanımı}

Günümüze kadar erken çocukluk çağı çürüklerinin (EÇÇ) çok sayıda tanıma sahip olması bu kompleks hastalığın çok faktörlü etyolojisi ve teşhis kriterleri üzerinde birtakım karmaşıklıklara sebep olmuştur. Amerikan fizikçi Abraham Jacobi, kendi çocuklarında gözlemlemesi sonucunda EÇÇ'nin klinik görüntüsünü ilk tanımlayan kişi olmuştur (Jacobi 1862). Ardından, 1930'lu yıllarda Beltrami "Les Dent Noire de Tout-Petits (çok küçüğün siyah dişleri)" olarak ve 1962 yılında Fass "nursing bottle mouth" şeklinde tanımlamıştır (Beltrami 1932, Fass 1962). Ayrıca, literatürde çürüğün klinik görünümü ve etyolojisi sebebiyle, "Melanodonti Infantil", "Baby Bottle Mouth Caries", "Nursing Caries", "Rampant Caries",

\footnotetext{
${ }^{1}$ Karadeniz Teknik Üniversitesi Diş Hekimliği Fakültesi Pedodonti Anabilim Dalı, Trabzon

${ }^{2}$ Recep Tayyip Erdoğan Üniversitesi, Rize
} 
"Baby Bottle Tooth Decay" ve "Labial Caries" gibi farklı isimlerle adlandırımıştır (James ve ark. 1957, Winter ve ark. 1966, Goose 1967, Derkson ve Ponti 1982, Arkin 1986, Ripa 1988, Bruered ve ark. 1989, Kaste ve Gift 1995, Horowitz 1998, Tinanoff ve ark. 1998, Drury ve ark. 1999, Ismail ve Sohn 1999).

Günümüzde ise; yetmiş bir aylık ve daha küçük çocuklardaki bir veya daha fazla çürük lezyonu (kaviteli ya da kavitesiz), çürüğe bağlı diş kaybı veya herhangi bir süt dişinde dolgulu diş yüzeyinin varlığı için EÇÇ terimi kullanılmaktadır. Üç yaşından küçük çocuklarda herhangi bir düz yüzey çürüğü belirtisi ise şiddetli erken çocukluk çağı çürüğünün (Ş-EÇÇ) göstergesi olmaktadır. Şiddetli EÇÇ; 3 yaşında en az 4, 4 yaşında en az 5 ve 5 yaşında en az 6 çürük, eksik ya da dolgulu diş yüzey sayısı olarak adlandırılmaktadır (AAPD 2008).

\section{Erken çocukluk çağı çürüklerinin prevelansı}

Son on yıl boyunca bilimsel çalsşmalardan edinilen genel görüş; diş çürüklerinde önemli ölçüde azalma olduğunu rapor ediyor olsa da EÇÇ gelişmiş ve gelişmekte olan ülkelerde hala ciddi bir sağlık sorunu olmaya devam etmektedir (Weinstein ve ark. 1994, Vadiakas 2008, Colak ve ark. 2013). Pek çok ülkeden diş çürüğü ile alakalı epidemiyolojik datayı içeren bir literatür araştırmasında EÇÇ prevelansındaki küresel artış vurgulanmaktadır (Bagramian ve ark. 2009, Fung ve ark. 2013). Farklı ülkelerde okul öncesi çocuklardaki diş çürük prevelansını gösteren son çalışmalar Tablo 1'de gösterilmiştir.

Tablo 1.

Farklı ülkelerde okul öncesi çocuklardaki diş çürüğü prevelansı

\begin{tabular}{|llccc|}
\hline Çalışma (Yıl) & Ülke & $\begin{array}{c}\text { Çocuk } \\
\text { sayısı }\end{array}$ & Yaş & $\begin{array}{c}\text { Prevelans } \\
\text { (\%) }\end{array}$ \\
\hline Ferreira ve ark. (2007) & Brezilya & 1.487 & $0-5$ & 40 \\
\hline Li ve ark. (2012) & Çin & 1.850 & 5 & 64 \\
\hline Carino ve ark. (2003) & Filipinler & 448 & 5 & 94 \\
\hline Autio-Gold ve ark. (2005) & Florida & 221 & 5 & 48 \\
\hline Cleaton-Jones ve ark. (2008) & Güney Afrika & 7.185 & $2-5$ & 59 \\
\hline Simratvir ve ark. (2009) & Hindistan & 609 & $3-6$ & 59 \\
\hline Pitts ve ark. (2007) & İngiltere & 216.873 & 5 & 38 \\
\hline Mora ve ark. (2000) & İspanya & 173 & $2-5$ & 37 \\
\hline Ferro ve ark. (2007) & İtalya & 3.401 & 5 & 31 \\
\hline Wigen ve ark. (2011) & Norveç & 1.348 & 5 & 11 \\
\hline Tsai ve ark. (2006) & Tayvan & 981 & $1-6$ & 52,9 \\
\hline Doğan ve ark. (2013) & Türkiye & 399 & $3-5$ & 40 \\
\hline Ozer ve ark. (2011) & Türkiye & 226 & $3-6$ & 49,6 \\
\hline Mantonanaki ve ark. (2013) & Yunanistan & 605 & 5 & 17 \\
\hline & & & &
\end{tabular}

Erken çocukluk çağı çürüklerinin etiyolojisi

Diş çürüğü bulaşıcı ve taşınabilen bir hastalıktır. Diş çürüğünün fazlasıyla agresif formu olan erken çocukluk çağı çürüğü ise; çok sayıda biyolojik, fizyolojik ve davranışsal risk faktörleri ile ilişkili olan multifaktöriyel bir rahatsızlıktır (Reisine ve Douglass 1998, Seow 1998, Wyne 1999). Mikroorganizmalar, substrat ve konağı içeren üç anahtar faktörden kaynaklandığı ifade edilmektedir, fakat EÇÇ'nin etiyolojisinde dental plak ve karyojenik bakterilere daha fazla önem verilmektedir (Begzati ve ark. 2014). Ayrıca, EÇÇ'nin sıklıkla uygun olmayan beslenme (Davies 1998) ve kötü ağız hijyen (Berkowitz 2003) alışkanlıkları ile ilişkili olduğu bildirilmiştir. Düşük sosyoekonomik statü (Kagihara ve ark. 2009, Tinanoff ve Reisine 2009), sık sık ara öğün tüketilmesi (Gussy ve ark. 2006, Tinanoff ve Reisine 2009), annenin sigara içmesi (Gussy ve ark. 2006), azınlık statüsü (Kagihara ve ark. 2009, Tomar ve Reeves 2009), annenin diş kaybı (Bedos ve ark. 2005), annenin yaptığı doğum sayısı 
(Russell ve ark. 2008), florlama (Gussy ve ark. 2006), bebek beslenme alışkanlıkları, ebeveyn eğitim durumu ve annenin tükürük $S$. mutans seviyesi (Kagihara ve ark. 2009), EÇÇ ile ilişkili olan sosyolojik ve çevresel faktörler arasında sayılmaktadır.

\section{Primer etiyolojik faktörler}

\section{Karbonhidrat tüketimi}

Sükroz, fruktoz, glikoz gibi şekerler ve diğer fermente olabilen karbonhidratların diş çürüğünün başlamasında ve ilerlemesinde hayati rol oynadığı kanıtlanmıştır (Paes Leme ve ark. 2006). Karyojenik olmayan gıdaları bile karyojenik hale dönüştüren sükrozun en önemli çürük yapıcı gıda olduğu bilinmektedir. Ayrıca, sükroz mutans streptokok ve laktobasil sayılarında artışı teşvik etmektedir. Çocukların fermente olabilen karbonhidratlardan zengin besinleri tüketmesinin EÇÇ'nin başlaması ve ilerlemesi üzerinde etkili olduğu bulunmuştur (Sobia ve ark. 2009). Diş çürüklerinin etiyolojisinde esas faktör, dişlerin şekere maruz kalma süresinin uzunluğudur. Bakteriler şeker alımını takiben 20-40 dakika içerisinde asit üretmektedir. Özellikle, uyku öncesinde ve uyku sırasında bu beslenme alışkanlıklarının devam etmesi EÇÇ riskini daha çok arttırmaktadır (Twetman ve ark. 2000). Gece boyunca azalmış tükürük akışından dolayı, denge remineralizasyondan çok demineralizasyona doğru kaymaktadır (Van Loveren 2004, van Palenstein Helderman ve ark. 2006).

Bilimsel açıdan kabul edilen genel görüş; bebeklere ilk altı ay boyunca yalnızca anne sütü verilmesini, 6 aydan 1 yaşa kadar da anne sütü ile beslenmenin devamını savunmaktadır (Salone ve ark. 2013). Anne sütünün sağlık üzerine olan pozitif etkilerine rağmen gün boyu ya da gece boyunca uzun süreli anne sütüne maruz kalmanın ve anne sütü ile beraber bebek maması verilmesinin EÇÇ için ciddi bir risk faktörü olduğu belirtilmiştir (AAPD 2014-2015). Bu durumun, bebek mamalarının tüketilmesinin plak PH'ını hızla düşürmesi ve oral kavite içindeki karyojenik mikroorganizma sayısındaki artış ile ilişkili olduğu açıklanmıştır (Erickson ve ark. 1998).

Uygun olmayan biberon kullanımının EÇÇ'nin etiyolojisi ve ciddiyeti üzerinde önemli rolü bulunmaktadır. Biberonla beslenmenin, özellikle, gece boyunca çocukların ağızlarında biberonla uyumasına izin verilmesinin karyojenik olduğu sonucuna varılmıştır (Twetman ve ark. 2000, Azevedo ve ark. 2005). Yapılan bir çalışmada anne sütü ile beslenen çocuklara kıyasla biberon kullanan çocukların EÇÇ'ye yakalanma riskinin beş kat fazla olduğu saptanmıştır (Du ve ark. 2000). Çocuk uyurken şekerli emzik ya da biberonla şekerli süt veya içecek verilmesinin EÇÇ ile ilişkili olduğunu bildiren çalışmalar da bulunmaktadır (Ripa 1988, Reisine ve Douglass 1998).

\section{Konak/Diş yapısı}

Bazı faktörler dişin çürüklere karşı olan yatkınlığını artırmaktadır. Çürük gelişimi ile ilgili bireye ait olan risk faktörleri: azalmış tükürük, immünolojik faktörler, mine defektlerinin varlığı, hipoplazi, immatür mine, diş morfolojisi, dişle ilişkili genetik faktörler (boyut, yüzey, fissür ve fossa derinliği) ve çapraşık dişlerdir (Sobia ve ark. 2009).

Tükürük çürüklere karşı bireyin en büyük savunma mekanizmasıdır. Yemekleri ve bakterileri dişlerden uzaklaştırmasının yanında asit üretimine karşı tamponlama görevini yapmaktadır. Ayrıca, mine remineralizasyonu için gerekli olan kalsiyum ve fosfat iyonları için depo görevi yapmaktadır. Uyku boyunca azalmış tükürük akış oranı tamponlama kapasitesinin azalmasına neden olarak, bu dönemde dişleri çürüklere karşı daha duyarlı hale getirmektedir (Schafer ve Adair 2000).

Mine immünolojik olarak inaktif olduğu için, $S$. mutans'a karşı esas immün cevabı büyük ölçüde tükürük immunoglobulin $A(\lg A)$, serum ve dişeti oluğu sıvısı yapmaktadır. Çocuklar oral mikroorganizmalar tarafından enfekte edildiğinde tükürük IgA antikorları gelişmektedir (Schafer ve Adair 2000). Erüpsiyon sonrasında ise, yeni ekspoz olmuş mine yüzeyi sürme sonrası final maturasyon aşamalarından geçmekte ve floridin de dahil olduğu ağız içerisindeki iyonların eklenmesiyle sertleşmektedir. Dişin çürüklere karşı en hassas olduğu periyot erüpsiyon sonrası ve son maturasyondan önceki dönemdir (Milgrom ve ark. 2000).

\section{Karyojenik mikroorganizmalar}

Yalnızca tükürük akışına maruz kalan mukozal yüzeylerden oluşan yeni doğan ağzında en çok bulunan bakteri Streptococcus salivarius'tur. Gibbons ve Houte (1975) S. mutans'ların epitelyal yüzeylere bağlanma kapasitelerinin zayıf olduğunu bildirmiştir. $\mathrm{Bu}$ nedenle, bu organizmalar süt dişlerinin sürmesini takiben kolonize olabilmektedir (Wan ve ark. 2001). Çocuklarda EÇÇ'nin ilerlemesinde ilk basamak karyojenik mikroorganizmaların ağız ortamında görülmesidir. Temel karyojenik mikroorganizmalar streptokoklar (S. mutans ve $S$. sobrinus) ve laktobasillerdir 
(Nurelhuda ve ark 2010, AAPD 2014-2015). S. mutans'ın çürük lezyon gelişiminin ilk evresinde aktif rol oynadığı bilinmektedir (Qin ve ark. 2008).

S. mutans dişler sürmeden önce iki farklı yolla bulaşabilmektedir. S. mutans anne veya bakıcı yoluyla vertikal olarak ve/veya aile içindeki ve çevredeki diğer bireyler (arkadaş ya da kardeş) aracılığıyla horizontal olarak bebeğe taşınabilmektedir. Mikroorganizmalar "enfektivite penceresi" olarak adlandırılan ve yaklaşık olarak 19-31. ayları kapsayan dönemde enfekte bireyden, özellikle anneden bebeğe kolayca geçebilmektedir. $S$. mutans'ın en büyük rezervuarı olan anne ya da bakıcının dudaktan öpmesi, bebeğin kaşığını veya emziğini temizlemek amacıyla kendi ağzına götürmesi ile bakteri transferi gerçekleşmektedir (Dasanayake ve Caufield 2002).

\section{Dental plak}

Diş çürükleri mikrobiyal dental plak zemininde başlamakta ve gelişmektedir. Plak içerisinde bulunan asidojenik ve asidürik bakteriler ( $\mathrm{S}$. mutans, S. sobrinus ve Laktobasiller) minenin demineralizasyonundan sorumlu tutulmaktadır (Becker ve ark. 2002). Alınan şekerin bu bakteriler tarafından metabolize edilmesi sonucu oluşan organik asit plak pH'ını hızlıca düşürmekte ve dişi çürüğe karşı duyarlı hale getirmektedir. Ayrıca, plak içinde üretilen bu asitler tükürüğün yıkama ve tamponlama kapasitesini azaltmaktadır (Sobia ve ark. 2009). Görülür plağın varlığı ve erken toplanmasının çocuklar arasında çürük görülme sıklığı ile ilişkili olduğu rapor edilmiştir (Tinanoff ve ark. 2002). Yapılan bir çalışmada, yalnızca görülür plağın varlığı ya da yokluğuna göre çocuklar doğru bir şekilde çürük risk gruplarına sınıflandırımıştır (Alaluusua ve Malmivirta 1994).

\section{Sekonder etiyolojik faktörler}

\section{Oral hijyen alışkanlıkları}

Dental plağın varlığı küçük çocuklarda çürük gelişimi için yüksek risk faktörü olarak kabul edilmektedir. Yapılan bazı çalışmalarda, çocuğun fırçalama alışkanlığı, fırçalama sıklığı, floridli diş macunu kullanıp kullanmaması diş çürüğü oluşumu ve ilerlemesi ile ilişkili olduğu rapor edilmiştir (Vanobbergen ve ark. 2001, Harris ve ark. 2004, Jones ve ark. 2005, Kaikure ve ark. 2015, Ghazal ve ark. 2015). Uyumadan önce dişlerini fırçalamayan çocuklar EÇÇ gelişimi açısından yüksek risk altında bulunmuştur (Harris ve ark. 2004). Küçük çocuklar kendi ağızlarını etkili bir şekilde temizleme beceresine sahip olamadıkları için ebeveynlerin en azından okula başlayana kadar çocuklarının dişlerini temizlemeleri önerilmektedir (Rosenblatt ve Zarzar 2004, Olatosi ve ark. 2015).

\section{Yetersiz florid alımı}

Diş çürüğünden korunmada en başarılı ve yaygın metod, lokal florid uygulamalarıdır (Ripa 1988, Walsh ve ark. 2010). Oral kavitenin içerisinde floridin devamlı bulunması demineralizasyon boyunca mineral kaybını azaltıp remineralizasyonu hızlandırarak minenin direncini arttırmaktadır (ten Cate ve Featherstone 1991, Davies 1998, Oliveira ve ark. 2014). Yapılan bir derleme, floridlenmiş içme sularının çocuklarda diş çürüğü gelişimini azaltmada etkili olduğunu belirtmiştir (IheozorEjiofor ve ark. 2015). Aynı derlemede florlanmış suyun okul öncesi çocuklarda dmf-t skorunu \%35 oranında azalttığı ifade edilmiştir. Daha uzun süre tükürük içindeki florid konsantrasyonunun korunmasını sağladığı için florürlü diş macunu ile düzenli diş temizleme ve uyumadan önce diş fırçalama çürük kontrolü için önemli kriter olarak kabul edilmektedir. Sistematik derlemeler, florürlü diş macunun okul öncesi çocuklarda diş çürüklerini azaltmada etkili olduğunu göstermiştir (Walsh ve ark. 2010, dos Santos ve ark. 2013, Wulaerhan ve ark. 2014, Kaikure ve ark. 2015), fakat florürün diş fırçası üzerine limitli olarak yerleştirilmesi ile yutulan florür miktarı kontrol edilmelidir. Ayrıca, sistematik derlemelerden edinilen bir diğer bilgi de, \%2.26'ık florür cilası, 3-6 ay aralıklarla uygulandığında, okul öncesi çocuklarda diş çürüklerini azaltmada etkili bulunmuştur (EAPD 2009, Marinho ve ark. 2013, Weyant ve ark. 2013).

\section{Ebeveynlerin eğitim seviyesi}

Sağlığın korunmasında toplumun sosyal yapısı ve bu yapı içerisinde eğitim seviyesi göz önünde bulundurulmaktadır. Ebeveynlerin eğitim seviyesinin çocuklarda EÇÇ'nin varlığı ve ciddiyeti ile ilişkili olduğu gösterilmiştir. Yüksek seviye eğitim almış ailelerin çocuklarında düşük çürük prevalansı ve dmf-t skorları saptanmıştır (Stephen ve ark. 2015). Milgrom ve ark. (2000) annenin sadece karyojenik bakteri rezervuarı olmadığını, çocuğunun genel sağlığına gösterdiği ilgisi kadar onun dental bilgisi ve tutumunun da çürük riskini azaltmak için önemli faktörlerden birkaçını teşkil etmekte olduğunu söylemiştir. Eğitim seviyesi düşük olan annelerin çocuklarının ağız sağlığı hakkında yetersiz bilgi sahibi oldukları belirlenmiştir (Jin ve ark. 2003). Ayrıca, eğitimsiz annelerin koruyucu programlara katılmasını teşvik etmenin de oldukça güç olduğu görülmüştür (Jose ve King 2003). 


\section{Sosyo-ekonomik faktörler}

Sosyal sınıf EÇÇ riskini pek çok şekilde etkileyebilmektedir. Düşük ekonomik tabakadan olan bireyler, profesyonel ağız sağlığı hizmetlerinden yararlanmalarını ve sağlıklı bir çevrede yaşamalarını tehlikeye atacak finansal, sosyal ve materyal dezavantajları yaşamaktadır (Jose ve King 2003). Bireyin sosyo-ekonomik durumu ile kötü sağlık şartları arasındaki güçlü ilişki kanıtlanmıştır (Fisher-Owens ve ark. 2007). Düșük gelir seviyesine sahip olan ailelerin çocuklarında düşük doğum ağırlığına sahip olma ve EÇÇ görülme riskinin daha fazla olduğu rapor edilmiştir (Fisher-Owens ve ark. 2007, Tiwari ve ark. 2014). Ailedeki çocuk sayısı, bebeğin doğum ağırlığı, kardeşler arasındaki yaş farkı, annenin doğum sırasındaki yaşının okul öncesi çocuklardaki çürük tecrübesi ile anlamlı derecede ilişkili olduğu gösterilmiştir (Wellappuli ve Amarasena 2012). Ayrıca, düşük gelirli ailelerin çocuklarının diş hekimini ilk ziyaretlerini daha büyük yaşta, daha az sıklıkta ve yanlızca dental problemleri olduğu zamanda gerçekleştirdikleri gösterilmiştir (Tsai ve ark. 2006).

\section{SONUÇ}

Okul öncesi çocuklarda en sık rastlanan hastalıkların başında gelen erken çocukluk çağı çürükleri ile ilişkili çok sayıda sosyal ve davranışsal risk faktörü bulunmaktadır; ancak EÇÇ, doğru bilgi ve yerinde müdahaleler ile önlenebilmektedir. EÇÇ'nin başarılı bir şekilde yönetimi ve tedavisi için çocuk diş hekimlerinin rehberliğinde çocuk doktorları, diş hekimi olmayan sağlık profesyonelleri, ebeveyn ve çocuklardan oluşan takım çalışmasının önemi vurgulanmaktadır. Günümüzde tedavi etmekten ziyade diş çürüklerinden korunmaya yönelik uygulamalar önem kazanmaktadır. EÇÇ'den korunmada ideal olan ise; bebekleri en geç 1 yaşında diş hekimine götürmek ve gerekli risk değerlendirmesini yaptırmaktır. 


\section{KAYNAKLAR}

Alaluusua S, Malmivirta R, 1994. Early plaque accumulation a sign for caries risk in young children. Community Dent Oral Epidemiol, 22, 273-276.

American Academy of Pediatric Dentistry, 2008. Definition of early childhood caries (ECC). From http://www.aapd.org/assets/1/7/D_ECC.pdf.

American Academy of Pediatric Dentistry, 2014-2015. Policy on early childhood caries (ECC): classifications, consequences and preventive strategies. Pediatric Dentistry, 36, 50-53.

Arkin EB, 1986. The Healthy Mothers, Healthy Babies Coalition: four years of progress. Public Health Repository, 101, 147-156.

Autio-Gold JT, Tomar SL, 2005. Prevalence of noncavitated and cavitated carious lesions in 5-yearold head start schoolchildren in Alachua County, Florida. Pediatric Dentistry, 27, 54-60.

Azevedo TD, Bezerra AC, de Toledo OA, 2005. Feeding habits and severe early childhood caries in Brazilian preschool children. Pediatric Dentistry, 27, 28-33.

Bagramian RA, Garcia-Godoy F, Volpe AR, 2009. The global increase in dental caries. A pending public health crisis. Am J Dent, 22, 3-8.

Becker MR, Paster BJ, Leys EJ, Moeschberger ML, Kenyon SG, Galvin JL, Boches SK, Dewhirst FE, Griffen AL, 2002. Molecular analysis of bacterial species associated with childhood caries. J Clin Microbiol, 40, 1001-1009.

Bedos C, Brodeur JM, Arpin S, Nicolau B, 2005. Dental caries experience: a two-generation study. J Dent Res, 84, 931-936.

Begzati A, Bytyci A, Meqa K, Latifi-Xhemajli B, Berisha $M, 2014$. Mothers' behaviours and knowledge related to caries experience of their children. Oral Health \& Preventive Dentistry, 12, 133-140.

Beltrami G, 1932. Les dents noires de tout-petits, La mèlanodontie infantile. Siècle Médical, Apr 4.

Berkowitz RJ, 2003. Causes, treatment and prevention of early childhood caries: a microbiologic perspective. J Can Dent Assoc, 69, 304-7.

Bruered B, Kinney MB, Bothwell E, 1989. Preventing baby bottle tooth decay in American Indian and Alaska native communities: a model for planning. Public Health Repository, 104, 631-640.
Carino KM, Shinada K, Kawaguchi Y, 2003. Early childhood caries in northern Philippines. Community Dent Oral Epidemiol, 31, 81-89.

Cleaton-Jones P, Williams S, Green C, Fatti P, 2008. Dental caries rates in primary teeth in 2002, and caries surveillance trends 1981-2002, in a South African city. Community Dental Health, 25, 79-83.

Colak H, Dulgergil CT, Dalli M, Hamidi MM, 2013. Early childhood caries update: A review of causes, diagnoses, and treatments. J Nat Sci Biol Med, 4, 29-38.

Dallı M Dulgergil ÇT, Hamidi MM, Mutluay AT, Doğan D, Akkuş Z. Different ECC patterns from Turkey: 4-Centered epidemiologic study for 1 to 3 years old children. Paper presented at the Across European Borders 5th Conseuro on Prevention, Restoration and Aesthetics, Istanbul, Turkey, 13-15 October, 2011.

Dasanayake AP, Caufield PW, 2002. Prevalence of dental caries in Sri Lankan aboriginal Veddha children. Int Dent J, 52, 438-444.

Davies GN, 1998. Early childhood caries a synopsis. Community Dent Oral Epidemiol, 26, 106-116.

Derkson GD, Ponti P, 1982. Nursing bottle syndrome: prevalence end etiology in a non fluoridated city. J Can Dent Assoc, 6, 389-393.

Dogan D, Dulgergil CT, Mutluay AT, Yildirim I, Hamidi MM, Colak H, 2013. Prevalence of caries among preschool-aged children in a central Anatolian population. J Nat Sci Biol Med, 4, 325329.

dos Santos AP, Nadanovsky $\mathrm{P}$, de Oliveira BH, 2013. A systematic review and meta-analysis of the effects of fluoride toothpastes on the prevention of dental caries in the primary dentition of preschool children. Community Dent Oral Epidemiol, 41, 112.

Drury TF, Horowitz AM, Ismail Al, Maertens MP, Rozier RG, Selwitz RH 1999. Diagnosing and reporting Early Childhood Caries for Research Purposes. J Public Health Dent., 59, 192-197.

Du M, Bian Z, Guo L, Holt R, Champion J, Bedi R, 2000. Caries patterns and their relationship to infant feeding and socio-economic status in 2-4year-old Chinese children. Int Dent J, 50, 385-389. 
Dye BA, Thornton-Evans G, Li X, lafolla TJ, 2015. Dental caries and sealant prevalence in children and adolescents in the United States, 2011-2012. NCHS Data Brief, 1-8.

Erickson PR, McClintock KL, Green N, LaFleur J, 1998. Estimation of the caries-related risk associated with infant formulas. Pediatric Dentistry, 20, 395-403.

European Academy of Paediatric Dentistry, 2009. Guidelines on the use of fluoride in children: an EAPD policy document. Eur Arch Paediatr Dent, 10, 129-135.

Fass EN, 1962. Is bottle feeding of milk a factor in dental caries? Journal of Dentistry for Children, 29, 245-51. Ferreira SH, Beria JU, Kramer PF, Feldens EG, Feldens CA, 2007. Dental caries in 0- to 5-year-old Brazilian children: prevalence, severity, and associated factors. Int J Paediatr Dent, 17, 289-296.

Ferro R, Besostri A, Meneghetti B, Olivieri A, Benacchio L, Tabaccanti S, Mazzoleni S, Favero G, Stellini E, 2007. Oral health inequalities in preschool children in NorthEastern Italy as reflected by caries prevalence. Eur $\mathrm{J}$ Paediatr Dent, 8, 13-18.

Fisher-Owens SA, Gansky SA, Platt LJ, Weintraub JA, Soobader MJ, Bramlett MD, Newacheck PW, 2007. Influences on children's oral health: a conceptual model. Pediatrics, 120, 510-520.

Fung MHT, Wong MCM, Lo ECM, Chu CH, 2013. Early Childhood Caries: A Literature Review. J Oral Hygiene \& Health, 1,107.

Ghazal T, Levy SM, Childers NK, Broffitt B, Cutter GR, Wiener HW, Kempf MC, Warren J, Cavanaugh JE, 2015. Factors associated with early childhood caries incidence among high caries-risk children. Community Dent Oral Epidemiol, 43, 366-374.

Gibbons RJ, Houte JV, 1975. Bacterial adherence in oral microbial ecology. Annual Review of Microbiology, 29, 19-44.

Goose DH, 1967. Infant Feeding and Caries of the Incisors: an epidemiological Approach. Caries Research, 1, 167-173.

Gökalp S, Doğan BG, 2006. "Türkiye Ağız-Diş Sağlığı Profili 2004", T.C Sağlık Bakanlığı Ana Çocuk Sağlığı ve Aile Planlaması Basımevi, Ankara, Türkiye.

Gussy MG, Waters EG, Walsh O, Kilpatrick NM, 2006. Early childhood caries: current evidence for aetiology and prevention. J Paediatr Child Health, 42, 37-43.

Harris R, Nicoll AD, Adair PM, Pine CM, 2004. Risk factors for dental caries in young children: a systematic review of the literature. Community Dent Health, 21, 7185.
Horowitz HS, 1998. Research issues in early childhood caries. Community Dent Oral Epidemiol, 26, 67-81.

Iheozor-Ejiofor Z, Worthington HV, Walsh T, O'Malley L, Clarkson JE, Macey R, Alam R, Tugwell P, Welch V, Glenny A, 2015. Water fluoridation for the prevention of dental caries. The Cochrane Database of Systematic Reviews 2015, 6, CD010856.

Ismail Al, Sohn W, 1999. A systematic review of clinical diagnostic criteria of early childhood caries. J Public Health Dent, 59, 171-191.

Jacobi A, 1862. Dentition: Its Derangements. A Course of Lectures Delivered in the New York Medical College. New York: Ballière Brothers.

James PMC, Parfitt GJ, Falkner F, 1957. A study of the aetiology of labial caries of the deciduous incisor teeth in small children. British Dental Journal, 103, 37-40.

Jin BH, Ma DS, Moon HS, Paik DI, Hahn SH, Horowitz AM, 2003. Early childhood caries: prevalence and risk factors in Seoul, Korea. J Public Health Dent, 63, 183-188.

Jones S, Burt BA, Petersen PE, Lennon MA, 2005. The effective use of fluorides in public health. Bull World Health Organ, 83, 670-676.

Jose B, King NM, 2003. Early childhood caries lesions in preschool children in Kerala, India. Pediatric Dentistry, 25, 594-600.

Kagihara LE, Niederhauser VP, Stark M, 2009. Assessment, management, and prevention of early childhood caries. J Am Assoc Nurse Pract, 21, 110.

Kaikure MK, Thomas A, Shetty SB, Jose T, Pidamale R, Kaikure SL, 2015. The Prevalence of Early Childhood Caries (ECC) and Its Associated Risk Factors Among Immigrant Tibetan Pre-School Children in Bylakuppe, Mysore, India. Science J Public Health, 3, 384-390.

Kaste LM, Gift HC, 1995. Inappropriate infant bottle feeding: Status of the Healthy People 2000 Objective. Arch Pediatr Adolesc Med, 149, 786791.

Law CS, 2013. Management of premature primary tooth loss in the child patient. J Calif Dent Assoc, $41,612-618$.

Li CR, Zeng XL, Wang X, Xu W, Chen X, 2012. Analysis of caries status among 5 -year-old children in Shanghai from 2008 to 2011. Shanghai J Stomatology, 21, 451-454. 
Mantonanaki M, Koletsi-Kounari H, Mamai-Homata E, Papaioannou W, 2013. Prevalence of dental caries in 5year-old Greek children and the use of dental services: evaluation of socioeconomic, behavioural factors and living conditions. Int Dent J, 63, 72-79.

Marinho VC, Worthington HV, Walsh T, Clarkson JE, 2013. Fluoride varnishes for preventing dental caries in children and adolescents. The Cochrane Database of Systematic Reviews, 7, CD002279.

Milgrom P, Riedy CA, Weinstein P, Tanner ACR, Manibusan L, Bruss J, 2000. Dental caries and its relationship to bacterial infection, hypoplasia, diet, and oral hygiene in 6-to 36-month-old children. Community Dent Oral Epidemiol, 28, 295-306.

Mora Leon L, Martinez Olmos J, 2000. The prevalence of caries and associated factors in children 2-5 years old from the Almanjayar and Cartuja Health Centers of the capital Granada. Atencion primaria / Sociedad Espanola de Medicina de Familia y Comunitaria, 26, 398-404.

Muller M, 1996. Nursing-bottle syndrome: risk factors. ASDC J Dent Child, 63, 42-50.

National Health and Nutrition Examination Survey, 2016. Reduce the proportion of children aged 3 to 5 years with dental caries experience in their primary teeth. From https://www.healthypeople.gov/2020/data-search/

Nurelhuda NM, Al-Haroni M, Trovik TA, Bakken V, 2010. Caries experience and quantification of Streptococcus mutans and Streptococcus sobrinus in saliva of Sudanese schoolchildren. Caries Research, 44, 402-407.

Olatosi OO, Inem V, Sofola OO, Prakash P, Sote EO, 2015. The prevalence of early childhood caries and its associated risk factors among preschool children referred to a tertiary care institution. Niger J Clin Pract, 18, 493-501.

Oliveira GMS, Ritter AV, Heymann HO, Swift Jr E, Donovan T, Brock G, Wright T, 2014. Remineralization effect of CPP-ACP and fluoride for white spot lesions in vitro. J Dent, 42, 1592-1602.

Ozer S, Sen Tunc E, Bayrak S, Egilmez T, 2011. Evaluation of certain risk factors for early childhood caries in Samsun, Turkey. Eur J Paediatr Dent, 12, 103106.

Paes Leme AF, Koo H, Bellato CM, Bedi G, Cury JA, 2006. The role of sucrose in cariogenic dental biofilm formation-new insight. J Dent Res, 85, 878-887.

Pitts NB, Boyles J, Nugent ZJ, Thomas N, Pine CM, 2007. The dental caries experience of 5-year-old children in Great Britain (2005/6). Community Dent Health, 24, 5963.
Qin M, Li J, Zhang S, Ma W, 2008. Risk factors for severe early childhood caries in children younger than 4 years old in Beijing, China. Pediatric Dentistry, $30,122-128$.

Reisine S, Douglass JM, 1998. Psychosocial and behavioral issues in early childhood caries. Community Dent Oral Epidemiol, 26, 32-44.

Ripa LW, 1988. Nursing caries: a comprehensive review. Pediatric Dentistry, 10, 268-282.

Rosenblatt A, Zarzar P, 2004. Breast-feeding and early childhood caries: an assessment among Brazilian infants. Int J Paediatr Dent, 14, 439-445.

Russell SL, Ickovics JR, Yaffee RA, 2008. Exploring potential pathways between parity and tooth loss among American women. American Journal of Public Health, 98, 1263-1270.

Salone LR, Vann Jr WF, Dee DL, 2013. Breastfeeding: an overview of oral and general health benefits. J Am Dent Association, 144, 143151.

Schafer TE, Adair SM, 2000. Prevention of dental disease. The role of the pediatrician. Pediatr Clin North Am, 47, 1021-1042.

Seow WK, 1998. Biological mechanisms of early childhood caries. Community Dent Oral Epidemiol, 26, 8-27.

Simratvir M, Moghe GA, Thomas AM, Singh N, Chopra S, 2009. Evaluation of caries experience in 36 -year-old children, and dental attitudes amongst the caregivers in the Ludhiana city. J Indian Soc Pedod Prev Dent, 27, 164-169.

Sobia Z, Soraya, YH., Allauddin, S, 2009. Early childhood caries: etiology, clinical considerations, consequences and management. Int Dent, 11, 2436.

Stephen A, Krishnan R, Ramesh M, Kumar VS, 2015. Prevalence of early childhood caries and its risk factors in 18-72 month old children in Salem, Tamil Nadu. J Int Soc Prev \& Comm Dent, 5, 95-102.

ten Cate JM, Featherstone JD, 1991. Mechanistic aspects of the interactions between fluoride and dental enamel. Crit Rev Oral Biol Med, 2, 283-296.

Tinanoff N, Kaste LM, Corbin SB, 1998. Early childhood caries: a positive beginning. Community Dent Oral Epidemiol, 26, 117-119. 
Tinanoff N, Kanellis MJ, Vargas CM, 2002. Current understanding of the epidemiology mechanisms, and prevention of dental caries in preschool children. Pediatric Dentistry, 24, 543-551.

Tinanoff N, Reisine S, 2009. Update on early childhood caries since the Surgeon General's Report. Academic Pediatrics, 9, 396-403.

Tiwari T, Quissell DO, Henderson WG, Thomas JF, Bryant LL, Braun PA, Albino JE, 2014. Factors Associated with Oral Health Status in American Indian Children. J Racial Ethn Health Disparities, 1, 148-156.

Tomar SL, Reeves AF, 2009. Changes in the oral health of US children and adolescents and dental public health infrastructure since the release of the Healthy People 2010 Objectives. Academic Pediatrics, 9, 388-395.

Tsai Al, Chen CY, Li LA, Hsiang CL, Hsu KH, 2006. Risk indicators for early childhood caries in Taiwan. Community Dent Oral Epidemiol, 34, 437-445.

Twetman S, Garcia-Godoy F, Goepferd SJ, 2000. Infant oral health. Dent Clin North Am, 44, 487-505.

Vadiakas G, 2008. Case definition, aetiology and risk assessment of early childhood caries (ECC): A revisited review. Eur Arch Paediatr Dent, 9, 114-125.

Van Loveren C, 2004. Sugar alcohols: what is the evidence for caries-preventive and caries-therapeutic effects? Caries Res, 38, 286-293.

van Palenstein Helderman WH, Soe W, van't Hof MA, 2006. Risk factors of early childhood caries in a Southeast Asian population. J Dent Res, 85, 85-88.

Vanobbergen J, Martens L, Lesaffre E, Bogaerts K, Declerck D, 2001. Assessing risk indicators for dental caries in the primary dentition. Community Dent Oral Epidemiol, 29, 424-434.

Walsh T, Worthington HV, Glenny AM, Appelbe P, Marinho VC, Shi X, 2010. Fluoride toothpastes of different concentrations for preventing dental caries in children and adolescents. Cochrane Database Syst Rev, CD007868.

Wan AK, Seow WK, Walsh LJ, Bird P, Tudehope DI, Purdie DM, 2001. Association of Streptococcus mutans infection and oral developmental nodules in pre-dentate infants. J Dent Res, 80, 1945-1948.

Weinstein P, Domoto P, Koday M, Leroux B, 1994. Results of a promising open trial to prevent baby bottle tooth decay: A fluoride varnish study. ASDC $\mathrm{J}$ Dent Child, 61, 338-41.

Wellappuli N, Amarasena N, 2012. Influence of family structure on dental caries experience of preschool children in Sri Lanka. Caries Res, 46, 208-12.
Weyant RJ, Tracy SL, Anselmo TT, Beltran-Aguilar ED, Donly KJ, Frese WA, Hujoel PP, lafolla T, Kohn W, Kumar J, Levy SM, Tinanoff N, Wright JT, Zero D, Aravamudhan K, Frantsve-Hawley J, Meyer DM, 2013. Topical fluoride for caries prevention: executive summary of the updated clinical recommendations and supporting systematic review. J Am Dent Association, 144, 1279-1291.

Wigen TI, Espelid I, Skaare AB, Wang NJ, 2011. Family characteristics and caries experience in preschool children. A longitudinal study from pregnancy to 5 years of age. Community Dent Oral Epidemiol, 39, 311-317.

Winter GB, Hamilton MC, James PMC, 1966. Role of comforter as an etiological factor in rampant caries of deciduous dentition. Arch Diseas Child, 417, 207-212.

Wulaerhan J, Abudureyimu A, Bao X, Zhao J, 2014. Risk determinants associated with early childhood caries in Uygur children: a preschool-based crosssectional study. BMC Oral Health, 14, 136.

Wyne AH, 1999. Early childhood caries: nomenclature and case definition. Community Dent Oral Epidemiol, 27, 313-315.

Yazışma Adresi:

Dr. Adem KUŞGÖZ

Karadeniz Teknik Üniversitesi

Diş Hekimliği Fakültesi Pedodonti AD

61080 Trabzon, Türkiye

Tel : + 904623774742

Faks : + 904623253017

E-mail: ademkusgoz@hotmail.com 